\title{
Formulating an International Growth Strategy: Considerations for MNC Decision Making Process
}

\author{
Yezdi H. Godiwalla ${ }^{1}$ \\ ${ }^{1}$ College of Business and Economics, University of Wisconsin-Whitewater, Whitewater, WI, USA \\ Correspondence: Yezdi H. Godiwalla, Management Department, College of Business and Economics, University of \\ Wisconsin-Whitewater, Whitewater, WI 53190-1790, USA.
}

Received: May 10, 2016

Accepted: May 31, 2016

Available online: June 1, 2016

doi:10.11114/ijsss.v4i7.1654

URL: http://dx.doi.org/10.11114/ijsss.v4i7.1654

\begin{abstract}
The purpose of the article is to review the issues relevant to the formulation of an MNC's international growth strategy. These include the ideas pertaining to the nature and extent of multi-nationality of the MNC, the degree of decentralization and the strategic and operating decision-making process. An effective international growth strategy of an MNC would provide it the focus that aims to maximize the organizational capabilities and the scope of the environmental opportunities. International growth strategies also leverage the differences in resources of the countries of the multinational corporation. There is a need for a systematic step-by-step approach to developing an international growth strategy. The quality of: (a) vision and goal clarity, (b) data gathering and sorting and reporting, and (c) analyses determine the quality of outcome of international growth strategy. International growth, competitiveness, flexibility, and long term investments in human and capital resources are the key to international growth. Organizational development should be perceived as an important ingredient for an $\mathrm{MNC}$ as it strives towards strategic progress. An effective international growth strategy of an MNC is the key to the continuous long term success of an MNC.
\end{abstract}

Keywords: international growth strategy, global organizational growth, MNC decision making process

\section{Introduction}

The formulation of an international growth strategy requires the matching of the multinational corporation's (MNC) global strengths-weakness profile, and global opportunities-threats profile. An overall global assessment is a prerequisite for formulating an MNC's overall corporate strategy, after which its growth strategy can be set. Several studies have reviewed the relationship between (degree of) multi-nationality and organizational performance (Agmon \& Lessard, 1977; Hirschey, 1981; Michel \& Shaked, 1986; Annavarjula \& Beldona, 2001). These studies analyzed if the firm's economic performance was related to the degree of internationalization of the firm.

A global orientation of an MNC would enable it to focus on the different global regions for choosing a superior match between its global strengths-weakness, and, global opportunities-threats. An MNC must view itself differently than a domestically-oriented organization which has international activities, particularly when these are subservient to its domestically-oriented interests. Table 1 provides various dimensions of an organization's multi-nationality. The more important aspects are the top management's global leadership, global mindset, ethnicity (preferably diverse ethnicity), and visionary approach to managing the overall organization. The emphasis should be on achieving effective use of resources, and the global spread of these resources. Global sales growth and operations should be congruent with the MNC's expectations of the future of the global economy and demographics. The greater the widespread availability of its products and services, the better is its growth on the international dimension.

Global competition drives an MNC to re-orient its internet flow of activities so that its value chain is more streamlined. This, in turn, would better align the activities to the market expectations and trends. International growth strategy is of vital importance of any sizeable organization. Annavarjula and Beldon (2001) provide a useful perspective of several approaches of international growth. These approaches include the diversifying or expanding of the international content of a firm on the following dimensions: (a) operation, that is to say, its value and volume of activities, sales, R\&D, manufacturing, (b) ownership, that is to say, particularly foreign owners, (c) orientation, that is to say, the intent of international breadth, strategy vision, and (d) diversification-spread of products, businesses. They have developed measures to evaluate the extent of internationalism of an organization. 
When a dynamic firm reaches its near maximum capacity from its domestic environments (markets, suppliers, human capital), it may seek foreign environments for its goal accomplishment. Its need to grow can be achieved by: (a) diversifying its products and/or businesses, technologies within the same regions; (b) diversifying its geographical regions, but keeping the same products, businesses and technologies; (c) diversifying its products, businesses, technologies, and also, its geographical regions. Thus, the measurement of (degree of) multi-nationality becomes the basis of evaluating a firm's international growth; distinguished from its domestic expansion, or domestic product or business or technological diversification.

Growth focused on international (as opposed to domestic) regions by dynamic firms does result in better performance on measures of (a) sales growth, (b) profitability (Grant, 1987), (c) positive performance relationships between multi-nationality and performance in single business firms (Buhner, 1987), (d) multi-nationality is positively related to performance (Ramaswamy, 1993), and (e) multi-nationality increases scale efficiency by three percent and also reduces economic risk by three percent (Al-Obaidan \& Scully, 1995). These are some of the considerations for growth issues.

Table 1. Dimensions of an Organization's Multi-nationality

\begin{tabular}{ll}
\hline 1. Top Management Ethnic Diversity & $\begin{array}{l}\text { Ethnic diversity of its top management; promotion of its } \\
\text { foreign units' managers into headquarters top management }\end{array}$ \\
\hline 2. Management's Mind-Set & World-view relatedness mind-set \\
\hline 3. Geographical Resource Spread & Global location of physical and human resources \\
\hline 4. International Sales (Growth) & $\begin{array}{l}\text { Expressed as a percent of total sales (of units as } \\
\text { well as dollar amount) }\end{array}$ \\
\hline 5. International Activities \& Operations & $\begin{array}{l}\text { Foreign productive/operational activities as a ratio of } \\
\text { domestic activities }\end{array}$ \\
\hline 6. International Products/Services Available & $\begin{array}{l}\text { Degree to which they are available in most of its } \\
\text { international markets }\end{array}$ \\
\hline 7. Local control of Foreign Units & $\begin{array}{l}\text { Self-determination of foreign units' strategic and } \\
\text { operating active }\end{array}$ \\
\hline
\end{tabular}

Description: The degree of an organization's international or multi-national spread is an important consideration because it would foretell its propensity to further expand into newer country markets and/or deeper into already expanded country markets.

\section{Literature Review and Implications to International Growth Strategy}

A survey of literature indicates the international growth can be assessed in MNC depending on the MNC size (or the level of activity), its ability to rapidly grow into same and/or different countries, and the diversity of its products, businesses, technologies, its customer groupings, and market regions.

A review of literature on the process of international growth provides insights which are often industry specific and which focus on the paths of effective international growth (Annavarjula \& Beldona, 2001; Barker and Cravens, 2001; Kuada \& Sorensen, 2000; Jain, 2000). Growth of an organization can be along several dimensions: products, businesses, technologies and geographical regions (within or outside the home country). These issues are well discussed for MNCs pursuing niche growth strategies in the work of Toften and Hammervoll (2011) in which they review growth approaches for the choice of innovation and market selection. In the case of international growth strategies for food products, which are often culturally sensitive, growth can be pursued using market penetration strategies when entering foreign country markets, as in the case of international marketing of cupcakes (Chen, Overby, Padgett, Long, Mellott, Vandermark, Kennedy, and Leah Boone, 2015). In hospitality industry, the effective transfer of knowledge, values and skills are the key to success in international growth (García-Almeida, and Yu, 2015). When there is the prospect of a foreign governmental partnership there can be available several different forms of international growth approaches, such as related and unrelated diversification by the MNC (Ortiz-de-Urbina-Criado, Montoro-Sánchez, Mora-Valentín, 2014). International growth focuses on growth prospects for the following strategic rationales (Hallback and Gabrielsson, 2013; Lal, Pitt \& Beloucif, 2000): (a) higher profitability, (b) faster growth rate, (c) greater safety of capital, (d) hedging local economic or industry cycles, and (e) diversifying cultural market regional orientations. (Note: a few of these may be overlapping.)

Rapid globalization would be a source of organizational strain (for coping with the scarcity of human, capital and other resources). This places special expectations on international growth process, as in the cases of an MNC pursuing entrepreneurial growth strategies when marketing to emerging market economies with a relatively easier country entry (Ali, 2000; Fletcher, 2000; Hallback and Gabrielsson, 2013.). A strong emphasis is the degree of spread in the internationalization of a firm. That is to say, the greater the spread, the better is the perceived internationalization (assuming all or most of the international growth has been beneficial to the firm). 
In a study of business entering emerging market countries and using a business-to-business marketing method, growth approaches using an organizational ecology approach appears to have been useful in that searching for resources has been a key issue (Todd, Javalgi, and Grossman, 2014). Their study found that firms operating in emerging markets (such as China and India) have to deal with similar difficulties in the host countries such as the lack of economies of scale and of other forms of inefficiencies, international and domestic competition, the need for adequate human and financial resources (same as in other types of countries). An additional problem in the case of expanding into emerging market countries is the further difficulty caused by the lesser developed infrastructure of the emerging market countries. A better use of the ecological approach that takes into consideration of the macro country situation is effective because such an approach uses the fuller and overall grasp of "the dynamics between resource utilization and growth" (Todd, Javalgi, and Grossman, 2014).

In a study by Hernández and Nieto (2016), they found that firms can grow internationally using two modes: inwardly (i.e. related to international supply chain operations) and outwardly (i.e. related to outbound marketing channels, such as serving or selling in foreign markets). They studied the differences in rates of international growth for firms adopting different international strategies, that is to say, those that perform only one type of international operation, and those that undertake both types of international operations simultaneously. The study used the logic that there would be greater benefits from using both inward and outward operations, because such connections that would give access to related and diverse knowledge. Their conclusions can so summarized, "Based on a sample of European SMEs from different sectors, the empirical findings indicate that undertaking inward and outward operations simultaneously exerts a greater positive effect on turnover growth than performing just one type of international operation. This simultaneous effect is significantly higher when these operations take place in the same foreign country. The findings provide support for the idea that the acquisition of country-specific knowledge allows firms to boost sales growth (Hernández and Nieto, 2016).

There can be various ways to measuring multi-nationality. For example, Annavarjula and Beldona (2001) used the following threshold for their study: (a) net sales of at least $\$ 10$ million, (b) at least ten percent of sales from foreign operations, and (c) at least ten percent of total assets located overseas. The same researchers further analyzed twenty six empirical studies from 1971 to 1995 (publication dates of these 26 studies). They reported eighteen studies which had positively related relationships of multi-nationality and MNC performance. Only two studies of the twenty six reported negative relationships between multi-nationality and MNC performance. While some six studies reported neutral (or statistically insignificant) relationships between multi-nationality and MNC performance. The researchers showed that (degree of) "multi-nationality was positively and linearly related to performance" (Annavarjula \& Beldona, 2001, 70).

Britain has had some three centuries of quite "united-ness" of Wales, Scotland, Northern Ireland, and England. When Tony Blair, the Labour Party leader, became the prime minister, he sought to spin off (or decentralize) the four member kingdoms. The decentralization is through "devolution," i.e. through the creation of legislatures in Scotland, Wales and Ireland. At the same time there is the centralizing force taking place, through pull towards Brussels, the center of the European Union. Thus, the two opposing forces of centripetal and centrifugal are simultaneously at work. For operating decision-making, there is decentralization. And for strategic decision-making, there is central coordination at London and further, at Brussels. For a pictorial representation, please see Figure 1. Fire 1 provides the relative decentralization and centralized coordination of decision-making in the United Kingdom under Tony Blair, and a multinational corporation.

Considerations for global growth may be evaluated on the multiple dimensions of market and region diversity, relative competitiveness in each market region, technological innovation rate, and market trends. These considerations become meaningful for growth related decision making because the global market forces would change the dynamics of the formulation of growth strategies. 


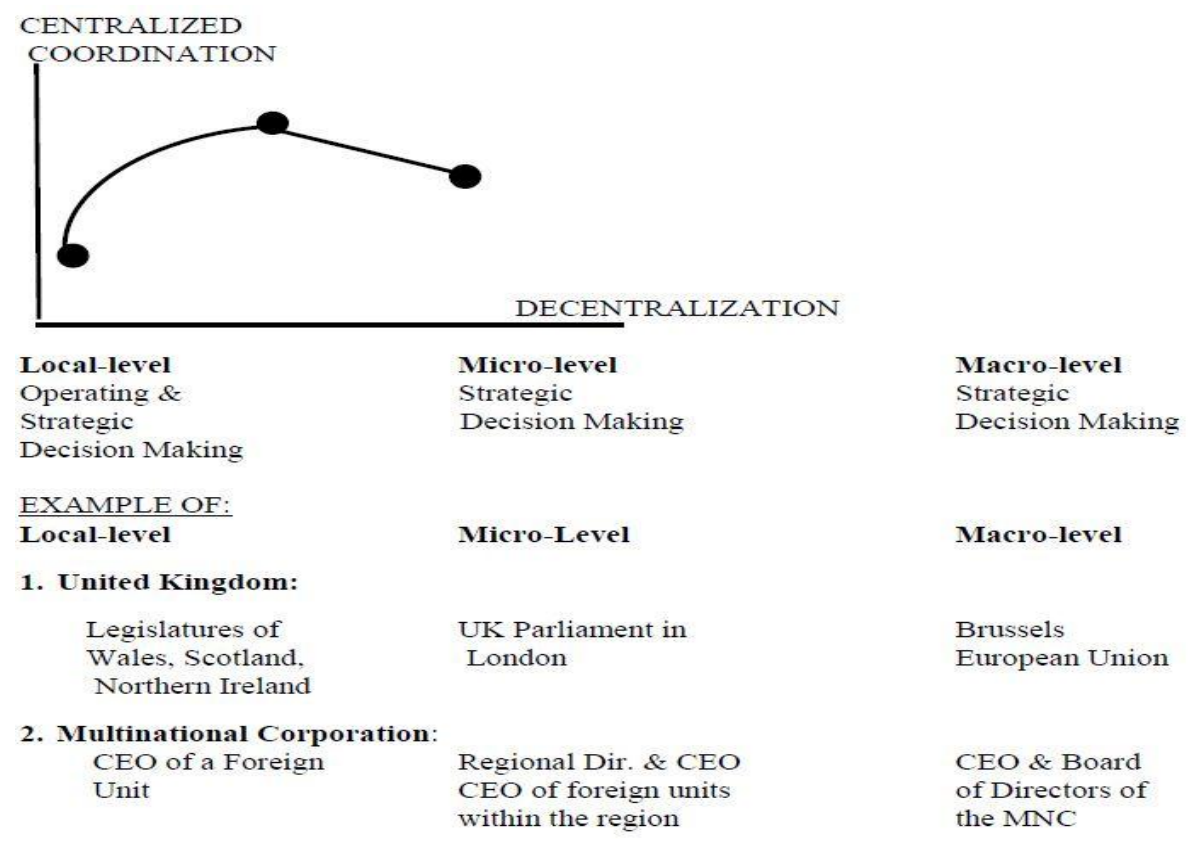

Figure 1. A Model of Decentralization and Centralization for Strategic and Operating Decision Making

Description: The dual pressures for centralization and decentralization are here considered. Centralization fulfills the need for top management control, while decentralization fulfills the capability to effectively respond to immediate task environments.

\section{A Model of Decentralization and Centralization for Strategic and Operating Decision Making}

The considerations for decision making process are important because growth and strategic issues are a core aspect of corporate strategy. A firm may be said to have generic issues, typically including: survival (requiring, for the safety of capital, the diversifying and/or consolidation of businesses, markets, and geographical regions), growth, expansion, profitability, competitiveness, and the development of human, capital and informational resources.

The achievement of a viable balance of centralization and decentralization is vital for a healthy organizational performance. With Tony Blair the opposing forces of decentralization (to legislatures of Wales, Scotland and Northern Ireland), and centralized coordination (at Brussels) are at work. Figure 1 portrays the similarity between Blair's model of the United Kingdom and a similar model of the multinational corporation.

In the case of a multinational corporation, the individual foreign units are allowed significant local responsiveness. This is done through the creation of a host country board of directors for the foreign unit. Unilever, the giant British counterpart of USA's DuPont, has long adopted this model for its organization. Local boards have a majority of local nationals and a few home country nationals. The foreign unit CEO is usually a host country or third country executive. This is designed to ensure a more effective local responsiveness and local responsibility. Under the proposed model, the foreign units are significantly autonomous in their local strategic decision-making, and completely autonomous for local operating decision-making.

The group of foreign units within a region should be coordinated. An example would be Ford of Europe and GM of Europe headed by their respective European top executive, or GE's (Medical System) top Asian region executive working out of Tokyo. The regional coordination would ensure better economic and strategic synthesis and more importantly, the elimination or reduction of redundancy and duplication. Further, produce design and manufacturing and operations would be integrated for more economic efficiency and competitive advantage.

Regional coordination has a worthwhile rational. Countries and their cultures within a region may, to some extent, have common essential characteristics borne out of allied cultural roots, affiliated social systems, similar economic and other infrastructures and quite similar managerial decision-making processes. These somewhat culturally and infrastructural-allied clusters of countries should be viewed as a larger little differentiated market and work place. And so, the region should be managed with a more meaningful regional coordination. The key is to help units to be responsive.

At the headquarters of the multinational corporation, the focus should be effective addressing of issues of global competition and industry economic and political trends. Emphasis should be strengthening the competitive hand of each foreign unit through superior R \& D and product attributes, substantial investments in human and capital resources, and 
above all, a vision that is oriented towards the future and the external environment. These issues are also depicted in Figure 2. Strategic and long term focus provides impetus for growth and competitiveness. On-going analyses of organizational needs and challenges would affect the reformulation of the long term vision, goals and strategy. These in turn would require changes in structure and culture. Growth and competitive pressures make it incumbent upon the organization to focus upon internal changes to respond to external challenges.

The MNC headquarters should focus upon the macro issues of global vision for the MNC as a whole. The emphasis is to focus on the overall organizational needs, particularly global: global competitiveness, organizational development, research and development, long term growth, improved organizational culture, substantial focus on flexibility. For the regional headquarters of a cluster foreign unit, the emphasis should be on growth of the regional development of the firm's performance. Also, regional coordination and integration of units' strategic activities and, to a lesser extent, operating activities would benefit from regional synergy and effectiveness. For each foreign unit, the focus should be host country responsiveness and competitiveness. These approaches are aimed at fostering improved organizational culture and renewed energy towards future growth and competitiveness.

An important consideration would be to focus on the centralized coordination of strategic decision making and action, and, the decentralization of operating decision making and action. Thus, the strategic decision making must involve the top, middle and lower levels of management, with the top level taking the strong leadership in coordinating the process. Such leadership would induce the burgeoning of creative ideas and alternatives for future actions from all levels. The operating decision making and action should be the prime purview of the lower levels of management in that they are directly interacting with the task environments and, therefore, they are in the best position to make proper decision and take proper actions on real time basis. This is particularly true in the case of joint partnerships with foreign governmental organizations where different forms of international growth approaches are considered, including related and unrelated diversification by the MNC (Ortiz-de-Urbina-Criado, Montoro-Sánchez, Mora-Valentín, 2014).

MNC Headquarters

Focus on: strategic vision, global competitive advantage, investments in long term human and capital resources through strategic coordination

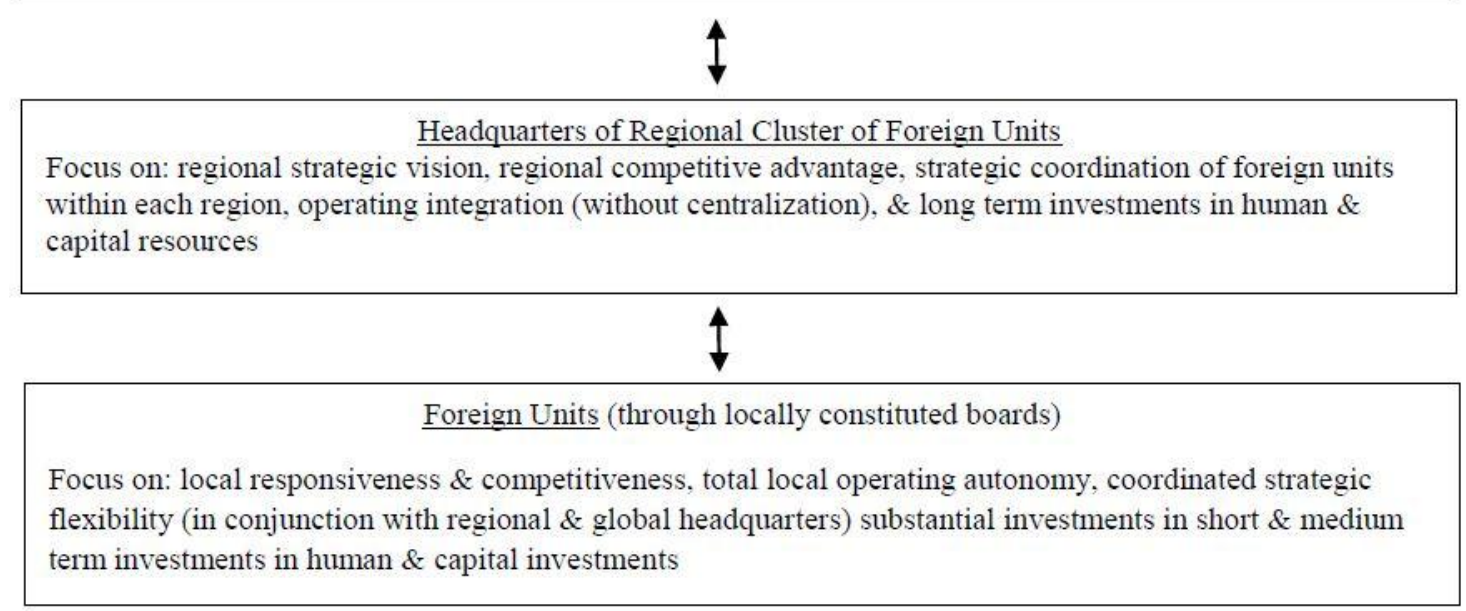

Figure 2. A Decision Making Model for a Multinational Corporation

Description: A model of a tri-level decision-making process for an MNC is important. Such a process would involve an orderly analysis and determination of the important aspects and factors for each decision-making topic. Further, it would ensure that a thorough review and decision-making is performed at each level, and, that the entire process is well coordinated.

\section{Organizational Culture}

An MNC's greatest challenge is to forge an acceptable global culture which is simultaneously functional to the MNC without being dysfunctional to the host countries of the foreign units. Figure 3 addresses this issue. The changing of organizational culture is an on-going process of growth and challenge to stay competitive. The figure portrays a three step process to change the organizational culture. It is important to note that the grassroots approach of including foreign units' values and needs are as important as the headquarters views and approach. An example of the need for the effective transfer of knowledge, values and culture as a prerequisite for success is in the hospitality industry, as studied 
by García-Almeida, and Yu (2015).

The evolution of new culture of a foreign unit must been seen to be consistent with the essential aspects of the national culture of its host country. Such an emphasis of congruence is vital if the MNC is to be globally progressive and also locally acceptable.

\section{Conclusion}

Growth of an MNC is an ongoing process of review of strategy, structure, culture, and technology. Their synthesis and synchronized pace among their changes would be helpful for smoother changes. Growth, competitiveness, flexibility, and long term investments in human and capital resources are the key to international growth. Organizational development should be perceived as an important ingredient for an MNC as it strives towards strategic progress.

The formulation of international growth strategies requires a systematic approach. Focus on vision and clarity and goal clarity is the first step because it resets the directional orientation, should this step be necessary. The focus then is the data gathering, sorting and analyses, and the formulation of the growth strategies.

Growth strategies essentially improve the MNC's organizational resource utilization process in the context of its task environment. The matching of organizational capabilities with environmental expectations and trends is a core concept of the organizational resource, utilization improvements. Another consideration is the MNC's effective leveraging of the host countries' economy, political, regulatory, cultural closeness.

In this way, the MNC's growth strategies provide an MNC the effective means to maximize its potential, become more competitive, and maximize its value to all its stakeholders in the home and host countries. The overall organizational culture of the headquarters, regional offices, and foreign subsidiary units should be well coordinated because a unified, common approach is vital, as portrayed in Figure 3.

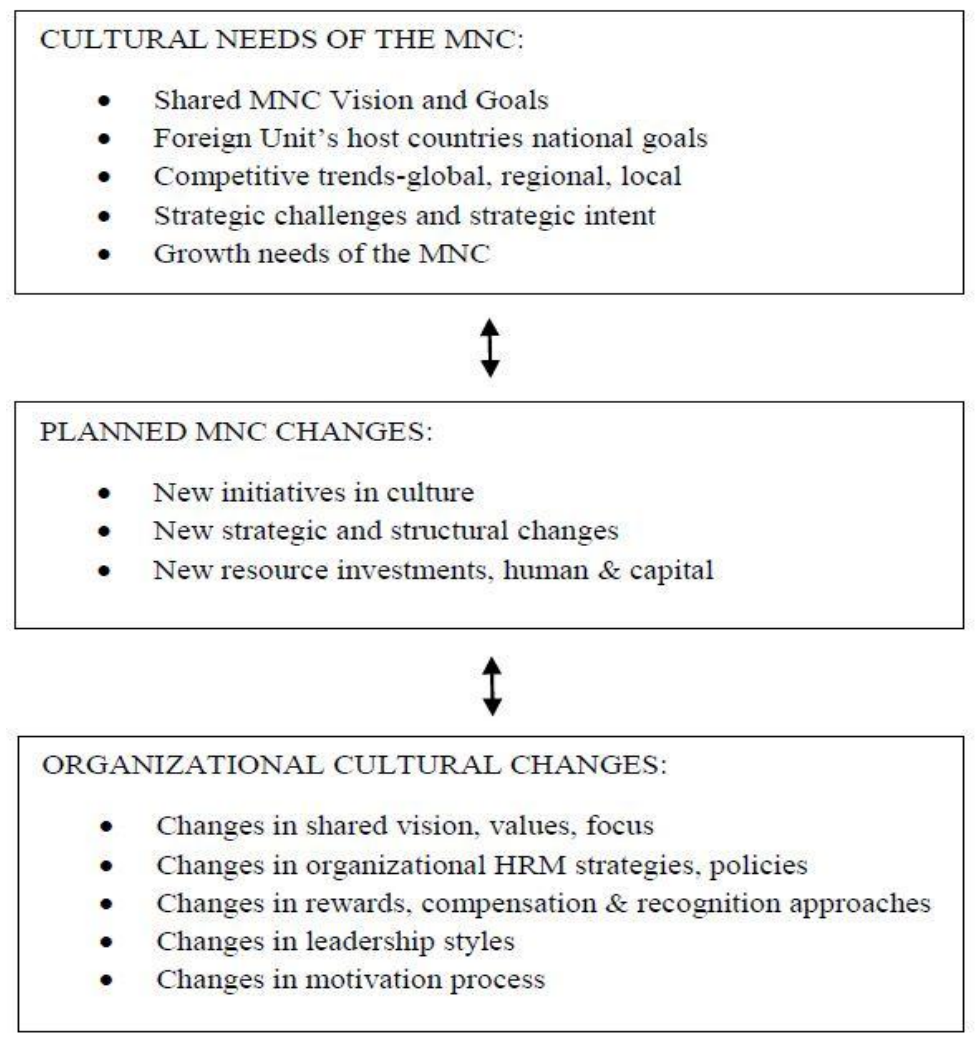

Figure 3. Changing MNC Organizational Culture

Description: After the rational, coordinated decision-making process is performed, the MNC needs to have everybody on board with a shared vision, mission, objectives and goals. They should have a common and agreed upon philosophy and views for the effective implementation of the overall corporate strategy.

\section{References}

Agmon, T., \& Lessard, D. (1977). Investor recognition of corporate international diversification. Journal of Finance, 32(9), 1049-1055. http://dx.doi.org/10.1111/j.1540-6261.1977.tb03308.x 
Aharoni, Y. (1991). On the definition of a multinational corporation. Quarterly Review of Economics and Business, $12(22), 59-76$

Ali, A. (2000). Globalization of Business: Theory and Practice. Binghampton, NY: Hayworth Press.

Annavarjula, M., \& Sam, B. (2001). A multidimensional model of corporate multinationality. Journal of Global Business, 12(22), 39-50.

Chen, D. C., Jeff, O., Barry, L., Padgett, Neda L., Lauren, H. M., Lauren, V., Nickolette, K., ... Leah, B. (2015). Sprinkles cupcakes: A case study of creating a successful internationalization strategy. Journal of the International Academy For Case Studies, 21(3), 193-204.

Fletcher, R. (2000). The impact of globalization on national sovereignty - An Australian perspective. The Journal of Current Research in Global Business, 2(2), 95-104.

García-Almeida, D. J., \& Yu, L. (2015). Knowledge Transfer in Hotel Firms: Determinants of Success in International Expansion. International Journal of Hospitality \& Tourism Administration, 16(1), 16-39. http://dx.doi.org/10.1080/15256480.2015.991986

Grant, R. M. (1987). Multinationality and performance among British manufacturing companies. Journal of International Business Studies, 18(3), 79-89. http://dx.doi.org/10.1057/palgrave.jibs.8490413

Grant, R. M. (1991). The resource based theory of competitive advantage: Implications for strategy formulation. California Management Review, 33, 114-135. http://dx.doi.org/10.2307/41166664

Hallback, J., \& Peter, G. (2013). Entrepreneurial marketing strategies during the growth of international new ventures originating in small and open economies. International Business Review, 22(6), 1008-1020. http://dx.doi.org/10.1016/j.ibusrev.2013.02.006

Hernández, V., \& María, J. N. (2016). Inward-outward connections and their impact on firm growth. International Business Review, 25(1), 296-306. http://dx.doi.org/10.1016/j.ibusrev.2015.05.009

Hirschey, M. (1981). Market power and foreign involvement by multinationals. The Review of Economics and Statistics, 343-345.

Jain, S. C. (1993). Market Evolution in Developing Countries. Binghampton, NY: Hayworth Press.

Kuada, J., \& Oval, J. S. (2000). Internationalization of Companies from Developing Countries. Binghampton, NY: Hayworth Press.

Label, W. A. (2001). Free Trade in the Americas: Is one hemispheric accord possible? Journal of Global Business, 12(22), 19-30.

Lal, D., Douglas, C. P., \& Ahmed, B. (2000). Theorizing in international business. Journal of Current Research in Global Business, 2(2), 72-81.

Mauri, A. J. (2001). Influence of industry and firm effects on global strategy: Assessing the heterogeneity of global industries using variance components analysis. Journal of Global Business, 12(22), 75-83.

Michel, A., \& Shaked, I. (1986). Multinational corporations vs. domestic corporations: Financial performance and characteristics. Journal of International Business, 18(3), 89-100. http://dx.doi.org/10.1057/palgrave.jibs.8490435

Ortiz-de-Urbina-Criado, M., Ángeles, M. S., \& Eva-María, M. V. (2014). Impact of growth strategy on mode of governance in alliances. International Business Review, 23(4), 838-848. http://dx.doi.org/10.1016/j.ibusrev.2014.01.002

Todd, P. R., Raj, G. J., \& David, G. (2014). Understanding the characteristics of the growth of SMEs in B-to-B markets in emerging economies: an organizational ecology approach. Journal of Business \& Industrial Marketing, 29(4), 295-303. http://dx.doi.org/10.1108/JBIM-08-2013-0189

Toften, K., \& Trond, H. (2011). International market selection and growth strategies for niche firms, International Journal of Entrepreneurship \& Innovation Management, 13(3), 282-295. http://dx.doi.org/10.1504/IJEIM.2011.039823

Will, G. F. (2000). Cheshire cat, cheddar man, Time, 72.

\section{(cc) BY}

This work is licensed under a Creative Commons Attribution 3.0 License. 